\title{
Percepções sobre a paternidade: descrevendo a si mesmo e o próprio pai como pai
}

\author{
Marília Reginato Gabriel \\ Universidade Federal do Rio Grande do Sul \\ Ana Cristina Garcia Dias \\ Universidade Federal de Santa Maria
}

\begin{abstract}
Resumo
Tornar-se pai pode ser experienciado tanto como um momento repleto de novos significados, transformações e responsabilidades, como um movimento de reavaliação dos valores e da criação tida pelos seus próprios pais. O objetivo desta pesquisa foi investigar as experiências e sentimentos de pais em relação à própria paternidade e em relação aos próprios pais. Participaram deste estudo oito homens, pais primíparos, com idades entre 28 e 41 anos, que responderam a uma entrevista semiestruturada. A análise de conteúdo dos relatos revelou que os pais descrevem-se como participantes nas tarefas de cuidado, e também como pessoas atenciosas e preocupadas com a educação e a saúde de seu filho. Diferenças e semelhanças em relação ao próprio pai no modo de exercer a paternidade mostram que, ao mesmo tempo em que desejam reproduzir os acertos dos pais, também buscam não repetir os erros.
\end{abstract}

Palavras-chave: paternidade; pai; relações familiares.

\begin{abstract}
Perceptions about fatherhood: describing himself and his own father as father. Becoming a father can be experienced both as a time replete with new meanings, transformations and responsibilities, as well as a period of re-evaluation of values and of own father childrearing behavior. The aim of this study was to investigate the experiences and feelings of fathers regarding their fatherhood and their own fathers. Participants were eight men, primiparous fathers, aged between 28 and 41 years who responded a semi-structured interview. Content analysis of the reports revealed that fathers describe themselves as participants in the tasks of caring, and also attentive and concerned with the child's education and health. Differences and similarities in relation to their own fathers childrearing practices show that, at the same time they want to reproduce their own fathers's succesfull behaviors, they also try to avoid what was considered mistakes.
\end{abstract}

Keywords: fatherhood; father; family relationships.

$\mathrm{A}$ concepção de parentalidade e do modo como se entende o sistema familiar se modificaram ao longo dos anos, principalmente ao serem questionados os papéis e funções do ser homem/pai, mulher/mãe e família na sociedade contemporânea (Cabreira, Tames-LeMonda, Bradley, Hofferth, \& Lamb, 2000). Um novo entendimento sobre as relações se instaurou e hoje as famílias possuem as mais diversas configurações, onde as figuras de pai e mãe, antes rigidamente demarcadas, vêm se diluindo, dando lugar a uma forma mais flexível e afetuosa de se relacionar (Fuster \& Ochoa, 2000). Desta maneira, o ser pai é um papel que se encontra em ampla transformação. Percebe-se que uma nova postura é exigida do homem, não só pela etapa do ciclo vital no qual ele está ingressando, na qual novas funções são esperadas, mas também pela sociedade e principalmente pela mídia, que cobra do homem ser um pai mais próximo e envolvido com as questões da família e do filho. Não é mais aceito que o pai apenas pague as despesas do filho; ele deve despender um tempo com a criança, atuar na sua educação e cuidados e estar disponível emocionalmente para ela - aspectos estes essenciais para um adequado desenvolvimento emocional da criança (Freitas, Silva, Coelho, Guedes, \& Costa, 2009; Hennigen \& Guareschi, 2008; Staudt \& Wagner, 2008).

Para o homem, a gestação e o nascimento do filho são atravessados por diferentes significados, transformações e responsabilidades que antes não existiam. A parentalidade pode gerar inúmeros sentimentos e maneiras particulares de vivenciar a chegada da criança, o que pode resultar em uma ambivalência nos sentimentos (alegria e tristeza) e nos comportamentos (proximidade e afastamento) vividos pelo homem (Bornholdt \& Wagner, 2005). Do mesmo modo, tornar-se pai pode ser experienciado pelo homem como um momento tanto de reavaliação dos valores e da criação tida pelos seus próprios pais como de revisão da sua própria infância e adolescência, lembranças estas que podem levar o homem a 
viver a parentalidade como uma fase conflituosa permeada por angústias e fantasias (Gomes \& Resende, 2004).

Para os futuros pais, o primeiro bebê marca uma transição importante em suas vidas. O bebê, totalmente dependente, transforma as pessoas e os relacionamentos em seu entorno. Homem e mulher tornar-se-ão pai e mãe; no entanto, outras funções e identidades de suas vidas deverão se ajustar a esses novos papéis. Nesse sentido, tanto homens quanto mulheres costumam ter sentimentos confusos sobre ter filhos, que podem ir desde uma empolgação com a notícia até o sentimento de ansiedade e medo em relação à responsabilidade de cuidar de um filho e ao comprometimento de tempo e de energia que isso envolve (Freitas, Coelho, \& Silva, 2007; Krob, Piccinini, \& Silva, 2009, Staudt \& Wagner, 2008). A espera de um filho faz com que os pais criem expectativas de como será o seu relacionamento com o bebê e de como será o seu papel como pai. Enquanto alguns pais não conseguem imaginar-se desempenhando o papel paterno, outros apresentam expectativas definidas, planejando a educação e interação com a criança. Muitos pais pensam em ensinar o filho, aconselhá-lo e orientá-lo, oferecendo a possibilidade de escolher diferentes coisas, muitas das quais eles próprios não tiveram. Para isso, eles se baseiam na maneira como eles próprios foram educados, a exemplo de seus próprios pais (Levandowski \& Piccinini, 2006).

No exercício da paternalidade, o homem toma para si a responsabilidade de sustentar a casa e passa para a mãe o encargo das atividades de cuidado cotidianas que o filho exige, justificando que a mãe também possui tarefas específicas com o bebê, e que ele é o único que ampara a casa financeiramente (Piccinini, Silva, Gonçalves, Lopes, \& Tudge, 2004). É possível perceber que, ao mesmo tempo em que o pai deseja participar da vida do bebê, ele se mostra excluído. Isso ocorre especialmente em função de tradicionais diferenças de gênero presentes em nossa cultura. Cabe lembrar que o cuidado dos filhos é percebido socialmente como uma habilidade natural feminina (Bornholdt, Wagner, \& Staudt, 2007; Levandowski \& Piccinini, 2006; Piccinini et al., 2004).

Em função de expectativas culturais, o pai experimenta um aumento de suas responsabilidades, que se manifesta, principalmente, através das preocupações financeiras, as quais são expressas pelo medo de ser despedido e de não conseguir manter a família (Piccinini et al., 2004). Além da responsabilidade pelo dinheiro, o pai também se sente responsável pela manutenção de certa estabilidade no seu relacionamento com a mãe do seu filho e pela reorganização da relação, uma vez que a chegada de uma criança exige a constituição de uma família, na concepção de alguns autores (Freitas, Coelho, \& Silva, 2007; Levandowski \& Piccinini, 2006; Piccinini et al., 2004).

Com o nascimento do filho, o pai passa a vivenciar um papel e uma relação que, durante a gravidez, estava apenas em etapa de preparação, período em que fantasias de como será a experiência são alimentadas. Na vivência da paternidade, os pais procuram aproximar-se afetivamente dos filhos, participando do cotidiano e dividindo os cuidados com a mãe da criança (Romanelli, 2003). Além disso, os homens apresentam satisfação no seu desempenho como pais, mesmo que haja empecilhos na sua convivência com o filho, como a pesada carga horária do trabalho, afastando o pai de um lugar ideal (Silva \& Piccinini, 2007). De fato, na sociedade atual tem sido cada vez mais frequente ver homens assumindo esses sentimentos e se colocando como participantes ativos na vida da criança (Wall \& Arnold, 2007)

Ao serem retomados os aspectos históricos da construção da paternidade, pode-se perceber como a paternidade tradicional foi estabelecida e aos poucos desconstruída, numa movimentação que influencia de maneira intensa o modo como este fenômeno é vivido pelos homens atualmente (Staudt \& Wagner, 2008). Na sociedade patriarcal clássica, as questões do afeto e do cuidado eram menosprezadas em nome do poder social. A supremacia masculina estava associada às idéias de primazia, força, poder, dominação, agressividade e autoridade e submissão do outro (esposa e filhos, especialmente) (Muraro, 1992; Silva, 2007). A modernidade, por sua vez, trouxe consigo a autonomia humana, a busca pela liberdade e, ao mesmo tempo, questionamentos ao modelo tradicional de ser pai. A honra e a força física, tão valorizadas no patriarcado, dão lugar ao dinheiro e ao sucesso, colocando ao homem trabalhador da ordem industrial do capital o papel de provedor da família, afastando-se dela para conseguir sustentá-la financeiramente (Silva, 2007). Paralelamente, a busca por produção e lucro chamou a mulher para o mercado de trabalho. Com a entrada desta no mundo capitalista no século XX, a estrutura familiar precisou ser modificada, pois, neste momento, o lar deixou de possuir a dedicação exclusiva da mulher. A concomitante descoberta dos anticoncepcionais, a ativação do movimento feminista e a luta pelo controle da sua sexualidade fizeram com que a relação da mulher com o mundo se transformasse de maneira irreversível (Ramires, 1997).

$\mathrm{Na}$ medida em que a mulher se insere no mercado de trabalho, os homens começam a dividir com a esposa os trabalhos domésticos e a criação dos filhos, ou seja, ao mesmo tempo em que a mulher invade o espaço público, antes exclusivo do homem, este retorna para o ambiente privado com uma função antes exclusiva da mulher (Muraro, 1992; Staudt \& Wagner, 2008). Desta maneira, os espaços público e privado começam a se integrar, enquanto os antigos estereótipos se desintegraram - a mulher tem acesso ao poder e o homem acesso ao seu privado, ao seu corpo, às suas emoções. A inserção da mulher no mercado pontua, deste modo, a entrada em um processo de superação do antigo sistema patriarcal, sinalizando não só uma mudança estrutural na família e nas relações, como também marca uma mudança psíquica, uma mudança de pensamento, de paradigma do que é ser homem/pai e ser mulher/mãe (Hennigen \& Guareschi, 2008; Muraro, 1992; Sutter \& Bucher-Maluschke, 2008).

Para poder desempenhar estas funções da maneira esperada, o homem tem reconstruído seu papel e sua postura de ser pai. $\mathrm{O}$ homem deixa de ter seu papel social vinculado apenas ao poder econômico, sendo que os sentimentos passam a ser a âncora do relacionamento entre pais e filhos (Sutter \& Bucher-Maluschke, 2008). A experiência de ser filho em um modelo tradicional, geralmente frio e distante, faz os homens desejarem ser um pai diferente. Assim, a identificação do tipo de paternagem 
tida, mesmo sendo ela considerada negativa, faz com que os homens possam reavaliar esta prática e partir para um novo modelo (Gomes \& Resende, 2004). Ao reconhecer os próprios sentimentos a respeito do pai, indo mais além do que ser contrário ao seu modelo, o homem se permite ter uma vivência mais íntima com o filho, tornando-se ator de uma importante mudança nas relações pai-filho. Deste modo, ter a percepção da paternidade exercida pelo pai sobre si colabora para o sujeito reformular seus valores quanto ao modelo de pai que teve e o pai que considera ideal (Gomes \& Resende, 2004). Desta reavaliação, alguns pais concluem que gostariam de criar o filho da mesma forma como foram criados pelos seus pais (Levandowski \& Piccinini, 2006) ou ser mais presente, mais carinhoso e afetuoso (Gomes \& Resende, 2004).

Para o homem se constituir como pai, toma para si tanto o modelo tido de paternagem como o modelo de como um bom pai deve ser, no seu próprio imaginário. Mesmo assim, o homem não deixa de questionar estas concepções dadas a priori, tanto pela geração antecessora quanto pelas exigências da sociedade. Ao tomar esta atitude, o homem concebe uma nova e singular maneira de ser pai, baseando-se no que está vivenciando no momento - sentimentos, preocupações, expectativas, dúvidas - e nos espaços que estão sendo abertos para que ele exerça a sua paternidade de modo natural e único. O objetivo do presente trabalho é compreender como vêm sendo construídas as percepções de homens acerca da paternidade, especialmente enfocando como os homens se descrevem como pais e como estes descrevem seus próprios pais como pais.

\section{Método}

Participaram deste estudo oito homens com idades entre 28 e 41 anos, que moram na cidade de Santa Maria (Rio Grande do Sul, Brasil). Os critérios de inclusão para a participação na pesquisa foram: estar, no momento da coleta de dados, na primeira experiência de paternidade, ter idades entre 25 e 45 anos, o filho ter até 5 anos de idade e encontrar-se em união estável com a mãe da criança. A Tabela 1 apresenta a caracterização dos participantes.

Como estratégia de coleta, os pais foram contatados, inicialmente, através da escola infantil mantida pela Universidade Federal de Santa Maria-RS. Os pais foram contatados através de convites anexados nas agendas dos alunos, sendo que dos 15 pais convidados, três retornaram e participaram da pesquisa. Os pais também foram convidados através da página da universidade e da indicação de pessoas conhecidas. Nenhum pai que atendia aos critérios de inclusão na amostra entrou em contato pela página da universidade, desta forma, além dos três pais contatados através da creche, foram entrevistados cinco pais indicados por pessoas conhecidas das pesquisadoras.

Assim que o contato inicial foi estabelecido com os voluntários, foi marcado um encontro em local e horário da conveniência do participante, sendo estes a própria escola, o trabalho do pai ou a sua residência. Para a coleta dos depoimentos, foi utilizada uma entrevista semiestruturada baseada em questões construídas a partir da revisão de literatura. As entrevistas foram gravadas em áudio e posteriormente transcritas para análise. As questões norteadoras foram: Como você se descreve como pai? Como está sendo a experiência de paternidade para você? Como você descreve o seu pai como pai? O que você, como pai, percebe que faz igual/diferente ao seu pai?

Essas questões tinham o objetivo de investigar as experiências e sentimentos desses pais em relação às suas vivências frente à própria paternidade, e a relação que esses jovens pais possuem com os próprios pais. No encontro, foram explicados aos pais os objetivos e procedimentos do estudo, assim como outras informações previstas no Termo de Consentimento Livre e Esclarecido. Esta pesquisa foi aprovada pelo Comitê de Ética da Universidade Federal de Santa Maria-RS.

\section{Resultados e Discussão}

Foi realizada uma análise de conteúdo de Bardin (1977) para examinar as falas dos pais. As seguintes categorias temáticas

Tabela 1

Dados demográficos dos participantes

\begin{tabular}{|c|c|c|c|c|c|c|c|c|}
\hline Pai & $\begin{array}{l}\text { Idade } \\
\text { (anos) }\end{array}$ & Escolaridade & Ocupação & $\begin{array}{l}\text { Idade do } \\
\text { filho }\end{array}$ & $\begin{array}{c}\text { Idade } \\
\text { do avô } \\
\text { (anos) }\end{array}$ & $\begin{array}{c}\text { Idade da } \\
\text { esposa } \\
\text { (anos) }\end{array}$ & $\begin{array}{c}\text { Ocupação da } \\
\text { esposa }\end{array}$ & $\begin{array}{c}\text { Renda } \\
\text { familiar } \\
\text { (salários) }\end{array}$ \\
\hline Anderson & 30 & Ensino Superior & Militar & $\begin{array}{c}1 \text { ano e } 4 \\
\text { meses }\end{array}$ & 56 & 34 & Dentista & 14 \\
\hline Beto & 31 & $\begin{array}{l}\text { Ensino Superior } \\
\text { Incompleto }\end{array}$ & Militar & $\begin{array}{l}3 \text { anos e } \\
5 \text { meses }\end{array}$ & 61 & 25 & Do lar & 8 \\
\hline Carlos & 33 & Ensino Médio & Comerciante & 3 anos & 52 & 27 & Comerciante & 6 \\
\hline Danilo & 41 & Ensino Superior & $\begin{array}{c}\text { Professor } \\
\text { universitário }\end{array}$ & $\begin{array}{c}1 \text { ano e } 7 \\
\text { meses }\end{array}$ & 84 & 40 & $\begin{array}{l}\text { Professora } \\
\text { universitária }\end{array}$ & 20 \\
\hline Elias & 34 & Ensino Superior & Vendedor & $\begin{array}{l}3 \text { anos e } \\
4 \text { meses }\end{array}$ & 59 & 33 & Do lar & 6 \\
\hline Fernando & 39 & Ensino Médio & Mecânico & 11 meses & 61 & 31 & $\begin{array}{l}\text { Professora } \\
\text { primária }\end{array}$ & 10 \\
\hline Gustavo & 28 & Ensino Superior & $\begin{array}{l}\text { Professor } \\
\text { universitário }\end{array}$ & 5 anos & 54 & 28 & Do lar & 10 \\
\hline Hélio & 40 & Ensino Superior & $\begin{array}{c}\text { Professor } \\
\text { universitário }\end{array}$ & $\begin{array}{c}1 \text { ano e } 5 \\
\text { meses }\end{array}$ & 70 & 34 & $\begin{array}{l}\text { Trabalha, não } \\
\text { especificado }\end{array}$ & 15 \\
\hline
\end{tabular}


emergiram previamente dos objetivos da pesquisa e foram consolidadas através das falas dos participantes: a) Eu como pai; b) Meu pai como pai; e c) Semelhanças e diferenças entre mim e meu pai entre si e o pai. A seguir, apresenta-se a caracterização de cada categoria, exemplificadas através dos relatos dos participantes, que tiveram seus nomes trocados.

\section{Eu como pai}

Os participantes percebem-se como pais presentes no cotidiano do seu filho, participando ativamente da sua educação e dividindo as tarefas de cuidados com a mãe da criança. Os pais descrevem-se como "carinhosos", "atenciosos", "atentos", "preocupados" com o filho, o que qualifica o tipo de participação prestada a ele. Muitas vezes o pai adapta todo seu conjunto de atividades, principalmente o trabalho e a vida social, em função do exercício desse novo papel. Exemplo: "Eu acho que eu sou um pai que participa, é o que eu vejo o pessoal comentar bastante como eu sou, né, um pai participante". "Eu faço questão de procurar não perder nada do desenvolvimento dele" (Anderson, 30 anos).

Ser um pai presente também implica dividir com a mãe os cuidados básicos do filho, é participar "não só dos bons, mas dos maus momentos", nas palavras de um dos participantes. Os pais apontam que atividades tipicamente exercidas pela mãe em algumas famílias (relacionadas à divisão de papéis sexuais considerada mais tradicional), são igualmente compartilhadas entres ambos os pais, fazendo com que, tanto homem quanto mulher dispensem na assistência do filho a mesma quantidade de tempo. Os pais avaliam de maneira negativa a divisão desproporcional de tarefas ou papéis entre pai e mãe em outros casais conhecidos, pois consideram que, nestes casos, o pai assume um papel apenas de recreador ou ajudante da mãe, e não de pai de fato do filho. Eles observam que a divisão de tarefas no cuidado é efetivamente determinada pelas necessidades do filho, sendo a "divisão" de tarefas realizadas pelo casal considerada ilusória.

Eu acho que eu sou atento, participativo e, claro, que, às vezes, a Denise (esposa) quer dividir as coisas bem ao meio, mas o Diego mostrou isso pra nós e pra ela, principalmente, é que ele prefere a mãe, né. Tem toda aquela questão materna mais próxima, mas eu me considero presente, né, acompanhando, partilhando. Não é aquela coisa de 'vai com a tua mãe' (risos), troco fralda (risos), essas tarefas assim. (Danilo, 41 anos)

Entre as principais funções dos pais, educar é percebido como uma das atividades mais significativas. Neste sentido, alguns homens descrevem a si mesmos como pais, baseando-se na maneira como eles percebem que educam o filho. Para eles, ser pai implica em educar o filho, o que significa colocar limites e regras, explicitando o que é certo e errado para o mesmo, ao mesmo tempo em que oferecem afeto (carinho e cuidado) ao filho. Esses pais buscam ser um modelo para os filhos.

Eu procuro ser amigo, procuro sempre fazer ele sorrir, que ele sempre perceba a minha presença, que ele me observe. Eu procuro ser bom o suficiente com ele. Na hora que eu acho que tem que ser mais firme assim com ele, eu vou ser né, e mostrar o porquê eu estou sendo assim com ele, né. (Elias, 34 anos)
Nesta primeira categoria, pode-se perceber que os pais reconhecem a importância da sua presença nas tarefas do dia-a-dia e na educação dos filhos. Dessa forma, tornam-se presentes e participantes ativos, tanto em momentos tidos como desagradáveis como troca de fralda, vacinação, refeições, castigos e do estabelecimento de limites, quanto nas situações agradáveis e brincadeiras. O amor dedicado ao filho é um componente importante na descrição de si como pai. Os pais relatam que procuram estar sempre ao lado do filho, aproveitando essas ocasiões, oferecendo carinho e atenção a ele. Observa-se que os pais descrevem as atividades realizadas com o filho com prazer e carinho. Para os homens, parece importante que seja considerado o tom afetivo com que exercem as tarefas parentais. A afetividade vinculada ao papel paterno redimensiona a participação masculina na família, sendo o carinho, amor e dedicação do pai, considerados quesitos essenciais para a construção da personalidade do filho e de uma relação saudável entre a díade.

A descrição feita pelos pais de si mesmos demonstra que os participantes avaliam-se positivamente no exercício de sua função de pai, principalmente por se considerarem "pais presentes", isto é, pais que buscam acompanhar o filho em todos os aspectos da sua vida. Cabe ressaltar que a própria participação neste estudo pode ser visto como um indicador de que esses pais se encontram envolvidos e preocupados com o exercício da paternidade. Ou seja, o interesse e o compromisso mostrados em relação à pesquisa sugere que esses pais são também interessados e comprometidos com o papel parental, havendo, por isso, o predomínio da descrição de experiências positivas nos resultados da pesquisa. É possível que os pais que não aceitaram o convite para participar do estudo possam apresentar algumas dificuldades no exercício da paternidade que os pais que participaram não possuem.

Os dados aqui encontrados são similares aos descritos por diversos estudos (Krob, Piccinini, \& Silva, 2009; Silva \& Piccinini, 2007; Sutter \& Bucher-Maluschke, 2008), que mostram que os pais se consideram presentes e próximos dos filhos, estando felizes no desempenho de suas funções paternas. Estes estudos apontam que os pais dividem as responsabilidades pelo filho com a mãe, pois acreditam na importância da sua participação na vida dos filhos, apesar de ter o tempo de contato com a criança reduzido por causa do trabalho.

Outro aspecto a ser destacado é que a participação desses pais nos cuidados do filho revela uma concepção de paternidade e participação do homem na vida familiar diferenciada de uma perspectiva tradicional de divisão de tarefas na família, na qual o cuidado da criança fica apenas aos cuidados da mãe, e o homem se encontra mais afastado do ambiente familiar (Fein, 1978; Staudt \& Wagner, 2008). O homem, ao sair do lugar de "marido ganha-pão", pode ocupar-se de outras funções dentro da família, compartilhando democraticamente atividades, antes exclusivas a um sexo ou outro. Assim, na medida em que a mulher saiu do ambiente privado, a família passou por uma série de transformações que contribuíram para que o homem fizesse o movimento contrário, ou seja, que voltasse a sua atenção à família e não somente ao trabalho. No contato direto com os filhos, o homem percebe que, para uma criança, não basta que 
as suas contas sejam pagas e que esteja bem alimentado e limpo; um filho exige o amor e o carinho de quem o cria, fazendo com que o homem perceba o quanto é imprescindível a sua presença e o seu afeto para com a criança.

A partir desses novos valores, os pais passam a ter um importante papel na vida do filho, atuando ativamente na sua educação e cuidados, preocupando-se em passar para a criança valores, regras morais e limites. Essa responsabilidade pela criação do filho também é descrita por outros autores (Silva \& Piccinini, 2007; Sutter \& Buccher-Maluschke, 2008), os quais indicam que os pais não se restringem a poucas atividades superficiais no cuidado com o filho, mas sim se ocupam ativamente de cuidados básicos e da educação moral e afetiva do filho.

\section{Meu pai como pai}

A percepção que o homem tem de seu pai revela certa ambiguidade na avaliação do modelo de paternagem recebido. Em alguns momentos o pai é tido como um bom pai e em outros é visto como um pai que poderia ter sido melhor ou diferente do que foi. Essas duas formas de ver o mesmo pai mostram que os filhos entendem que o seu genitor teve algumas falhas, mas que, nem por isso, torna-se um modelo inteiramente desclassificável. Ao também se encontrar desempenhando o papel de pai, o homem compreende o quão difícil é estar neste papel, reconhecendo com maturidade e sabedoria as qualidades e falhas que seu pai possui.

Quando a gente é pequeno o pai é o máximo, depois a gente vai se nivelando e vendo que não é bem assim. Vai descobrindo os defeitos e tudo mais, assim como nós temos, então é aceitável. Tu não pode querer que uma pessoa não tenha defeitos, então eu reconheço tanto os meus quanto os dele. Mas isso não impede de eu ter ele como parâmetro. (Gustavo, 28 anos)

Alguns participantes identificam no seu pai um homem que foi presente e carinhoso com os filhos, fazendo o possível para que tivessem um bom futuro e uma boa educação. Neste momento, os pais participantes reconhecem o seu pai como um bom pai, passível de ser admirado e seguido como modelo.

Carinho nunca nos faltou, a gente sempre teve muito. O pai sempre foi muito carinhoso com nós e continua sendo até hoje. Meu pai, eu tenho muito orgulho dele pela maneira difícil que ele nos criou. O pai sempre dedicou muito tempo pra nós, forçou, tentou fazer com que a gente estudasse. (Fernando, 39 anos)

Por representar uma figura positiva, a maneira como o pai desempenhou (e desempenha) seu papel com os filhos influencia no modo como os participantes enxergam o fenômeno da paternidade e no modo como eles desejam ser como pais. A paternidade exercida pelo próprio pai não é somente vista como um modelo, mas como o que idealmente um pai deveria ser.

Tem que ser presente, atencioso, amoroso. Eu vejo esses fatores, ensinar o filho a tomar decisões, ser seguro, isso eu aprendi com meu pai. Então tu não pode nem superproteger, nem soltar demais, tem que dar condições pra ele se formar e foi assim que eu fui educado. (Gustavo, 28 anos)
Ainda que a maioria dos participantes tenha se referido ao seu pai como um bom pai, apesar das eventuais discordâncias e diferenças, alguns homens se referiram ao pai como não sendo um bom pai ou com características que não devem ser seguidas. A falta de diálogo e abertura para que uma conversa pudesse se realizar, assim como a carência de preocupação com os filhos e a falta de afeto, são as principais falhas apontadas por alguns desses participantes quando falam de seu próprio pai.

Ele não foi um bom pai, sabe. Hoje eu percebo com o meu filho que ele poderia ter sido melhor comigo, com o restante dos meus irmãos, poderia ter agido de maneiras diferentes. Acho que faltou uma coisa que é muito importante que é mais diálogo, mais demonstração de carinho, mais demonstração de amor, mais respeito pela família, procurar levar a família em primeiro lugar, sabe. (Elias, 34 anos)

A experiência de paternidade vivenciada pelos participantes enquanto filhos e a sua avaliação desta vivência mostram que os pais dos entrevistados tiveram, na sua maioria, êxito na relação com seus filhos. Os participantes, mesmo ao colocar os aspectos negativos do pai, não o falaram com mágoa, mas como fazendo parte da personalidade do pai ou do padrão de relacionamento entre pai e filhos, considerado adequado na época em que viveram essa experiência.

A distância estabelecida entre si mesmos e seus pais é descrita através de um relacionamento, se não ausente, baseado na autoridade e na falta de afeto. Balancho (2004), em sua pesquisa com duas gerações de pais (estudo longitudinal) em Portugal, refere-se a esta percepção dos filhos como condizente com o que se esperava de um pai na época em que estes homens, hoje pais, eram crianças. O pai da geração anterior à atual parece possuir a missão de educar e disciplinar os filhos, tarefa que não exigia necessariamente presença constante e afeto nas intervenções. Os participantes desta pesquisa avaliaram seus próprios pais como bons no papel de educadores; porém, também revelaram que seus pais poderiam ter sido melhores nesse papel, se o tivessem exercido com afeto. Essa percepção pode ser o que explica, ao menos em parte, a ambiguidade dos homens ao descreverem seus pais.

O modo como o pai enxerga a sua criação por parte do seu próprio pai é essencial para a constituição de seu ideal de paternidade (Krob, Piccinini, \& Silva, 2009, Silva \& Piccinini, 2007; Staudt \& Wagner, 2008). Neste caso, o avô pode colaborar para uma construção favorável da paternidade ou ainda no sentido do homem ver no pai o que não quer para si. O que pode ser percebido, neste sentido, é a importância do exemplo paterno, que, mesmo não materializado através de ações diretas, é expresso na história de vida do avô, transmitida ao filho em diversas circunstâncias, com percalços e dificuldades inerentes ao cotidiano (Romanelli, 2003).

Muitos pais tomam o seu próprio pai como modelo de como um pai deve ser, o que revela a significativa influência que os pais têm na construção da imagem de paternidade que o filho desenvolverá no futuro. As informações encontradas no estudo americano de Masciadrelli, Pleck e Stuave (2006) vão ao encontro dos achados desta pesquisa de que o próprio pai é considerado um modelo de pai pelos filhos. Os autores 
questionaram pais (homens) quanto à existência de algum modelo que tivesse influenciado seu papel como pais, sendo que o próprio pai e a dupla parental (pai e mãe) foram os mais citados com 16\% e 37\%, respectivamente. Estes dados revelam o quanto os homens avaliam de forma positiva o desempenho dos seus próprios pais a ponto de os colocarem no lugar de modelo de conduta. Contudo, esse dado nos revela uma informação interessante a ser questionada em futuras pesquisas em relação a como a mãe ou mesmo a esposa influenciam na construção do modelo de paternidade. Esses autores encontraram, ainda, que os principais conteúdos aprendidos pelos homens com seus modelos de paternidade consistiram em responsabilidade, bons valores e paciência. Estes aspectos foram citados pelos pais do nosso estudo, pois o modelo (pai ou outras pessoas consideradas modelos) possuía essas características como pais ou como genitores, sendo que os filhos reconhecem os benefícios que o exercício dessas qualidades tiveram em seu desenvolvimento, procurando atualmente exercer a paternidade da mesma maneira. Isto quer dizer que há padrões de valores e características que são passados de geração em geração, com algumas adaptações ao mundo atual, mas ainda mantendo características essenciais do cuidado aos filhos.

No presente estudo, ao comparar a maneira como os participantes descrevem os seus pais e a si mesmos, pode-se dizer que, em alguns aspectos, também há transmissão intergeracional do modelo de paternidade, principalmente no que diz respeito à educação e afeto fornecido aos filhos. Contudo, há fatores que parecem não ter seguido a lógica da passagem de gerações. A abertura ao diálogo parece ser um fator que se modificou de uma geração para outra, sendo que os pais de hoje parecem desejar serem mais abertos e ainda mais carinhosos com seus filhos (Krob, Piccinini, \& Silva, 2009). Uma provável explicação para esta mudança de perspectiva na parentagem talvez seja a época em que os homens da amostra nasceram (décadas de 70 e 80), quando o afeto entre pais e filhos já estava sendo mais valorizado; no entanto, a abertura ao diálogo ainda era considerada um tabu entre pais e filhos (Silva, 2007).

\section{Semelhanças e diferenças entre si e seu pai}

Os pais participantes do estudo foram solicitados a citar as semelhanças e as diferenças que possuíam com seu pai em relação a este papel. As semelhanças apontadas pelos homens evidenciam que há características que aproximam e distanciam os dois modelos de paternidade discutidos - o modelo de paternidade recebido e o desempenhado atualmente. A relação vivida com o próprio pai é a referência mais próxima que o homem tem de como o papel paterno pode ser desempenhado. Posteriormente, esse modelo é avaliado e pode ser repetido, no todo ou em apenas alguns de seus aspectos, ou ainda não repetido.

Puxa da mente a tua criação, né, a tua educação. Eu acho que o instinto normal é você seguir mais ou menos a mesma linha. A não ser que você tenha tido um comportamento do teu pai que você fala: não, aquilo eu não vou fazer. E aquilo fica gravado na tua memória pra não fazer. Fora isso, a tua tendência é você seguir o que você já conhece, né, aquilo que tu viveu. (Anderson, 30 anos)
Entre os muitos fatores repetidos nas duas gerações, a maneira de educar, de ensinar o que é certo e o que é errado parece ser o aspecto mais significativo. As práticas exercidas como não usar a violência, ser rígido quando for necessário e explicar o porquê das suas atitudes são aspectos mencionados pelos pais como semelhantes aos modelos recebidos. Ser carinhoso e preocupado com o filho também são características reproduzidas por alguns participantes.

A rigidez na medida certa e o carinho na quantidade certa. Aliás, carinho nunca é demais, mas eu acho que nisso a gente é muito parecido e na preocupação também, na preocupação de dar esse caminho certo. Não basta fazer, você tem que estar preocupado em fazer, se não você talvez não faça. (Anderson, 30 anos)

Para outros homens, a proximidade com seus pais e a abertura para a conversa foram e ainda são aspectos inexistentes no relacionamento pai-filho. Em função disso, buscam estabelecer com seus próprios filhos uma relação diferenciada, caracterizada pela proximidade e o afeto. Eles reconhecem que, no momento histórico em que eram crianças ou adolescentes, o papel de pai se caracterizava mais pelo distanciamento e a rigidez, mas agora percebem que isso pode - e mesmo deve ser diferente.

Meu pai não tinha essa abertura pra gente conversar. Então, eu aprendi muita coisa no mundo, bastante coisa. Hoje, em cima daquilo que eu aprendi, que eu senti falta de não ter em casa, eu quero evitar que aconteça com meu filho, né. Que não se depare com os problemas na vida e não saiba como que vai ser, ninguém nunca disse para ele, uma luz, de como vai ser, como reagir. Eu tive algumas dificuldades na vida que, se eu tivesse uma orientação diferente, eu poderia ter sido diferente. Não me arrependo, mas tive que aprender, às vezes, quebrando a cabeça. (Fernando, 39 anos)

Outro ponto mencionado pelos participantes em que se perceberam semelhantes a seus pais foi a preocupação com os recursos financeiros e com o rendimento e aplicação no próprio trabalho. Antes da paternidade, o homem parece não compreender essa preocupação com a mesma significação que tem para o indivíduo que está na condição de pai e provedor. Quando passa a exercer o papel de pai, porém, a relação com o trabalho e a busca de sustento ganha saliência e torna-se um aspecto central na vida do homem-pai, da mesma forma como ocorreu na geração anterior.

A minha preocupação maior é o financeiro, sempre foi, como
pai. É uma cobrança que eu tinha com meu pai, que a visão que
eu tinha era essa, que é essa cobrança econômica, né. Tudo tem
custo, tudo é conta e não sei o que e no fim é no que a minha
vida se transformou. É aquela coisa que o filho só entende
quando passa, né. (Gustavo, 28 anos)

Alguns pais mencionaram que agiriam de maneira diferente de seus pais em relação ao jeito de ser e quanto ao modelo de vida a ser passado para o filho. Os comportamentos de despreocupação com os hábitos que passam para os filhos ou de sustentação da postura de "super-homem" são reprovados por alguns pais. Talvez seja importante colocar que as diferenças 
apontadas parecem tomar forma na prática do filho que agora também é pai. Antes disso, o homem parecia aceitar as explicações ou estilo de vida paterno; no entanto, estes aspectos parecem receber as críticas após a vivência de que é possível ser pai de outra maneira.

Quando me percebi como pessoa já sabia obedecer porque era uma cobrança é muito maior do que hoje, do que em relação com a minha filha né. O pai falou, é certo, não se discute. Algumas coisas eram proibidas e pronto, outras coisas era obrigado a fazer e não sabia nem porque era assim. Fui perceber depois que era assim porque o pai queria simplesmente. Então é um aspecto que eu vejo que é diferente da época que era filho $\mathrm{E}$ uma coisa que é diferente e, que, pelo menos eu acho que vai ser diferente em relação aos meus filhos, que o filho tem que aprender, não pela imposição, mas aos poucos precisa entender que tem uma razão de ser das coisas né. (Beto, 31 anos)

Nas semelhanças e diferenças citadas pelos participantes em relação ao seu modo de ser pai e o modo como seu pai foi/é como pai, pode-se perceber que alguns aspectos são passados adiante nas gerações e outros não. Os pais citam os aspectos positivos da sua criação e que estão sendo repetidos com seus filhos, revelando uma relação intergeracional em valores como preocupação com a educação, com o trabalho e afeto. Aspectos avaliados pelos participantes como negativos, como comunicação deficiente e rigidez, são refutados e em cima deles, construídas novas formas de agir.

No estudo de Weber, Selig, Bernardi e Salvador (2006) foram analisados elementos de transgeracionalidade entre três gerações de mulheres, sendo que os resultados encontrados assemelharam-se em parte aos do presente estudo. No que tange à variável relacionamento afetivo com relação à mãe, ficou demonstrada a intergeracionalidade na comparação entre a primeira e a segunda geração, o mesmo que aconteceu para alguns dos participantes homens do nosso estudo. Com as mães ficou evidenciada a transmissão intergeracional dos aspectos negativos, como punição inadequada, modelos inconsistentes, entre outras variáveis, o que não aconteceu com os pais participantes, os quais optaram por não repetir modelos negativos.

Contudo, as mudanças ocorridas nos casos de não transmissão, como no estudo com mulheres, realizado por Weber et al. (2006), e neste estudo com homens foram para melhor - mais envolvimento, mais afeto e maior comunicação entre mães/pais e filhos. Segundo as autoras do primeiro trabalho, a ausência de intergeracionalidade seria explicada pelas mudanças socioculturais pelas quais a sociedade passa ao longo dos tempos, já que não se confirmou a transmissão intergeracional em todos os aspectos avaliados. Outras duas hipóteses que pode justificar a não intergeracionalidade na transmissão de valores são: a busca pela quebra de padrões familiares e a maior divulgação de informações científicas a respeito de educação de filhos. Em alguns casos, percebe-se a intenção de modificação de comportamento ao avaliar que aquele anteriormente vivido não é adequado. Assim, percebe-se o desejo de mudança, que se torna responsável, em parte, pela inexistência ou fraca transmissão de valores vividos entre as gerações.
Já nos achados de Dias e Lopes (2003), as duas gerações de mães participantes utilizaram características semelhantes para descreverem-se a si próprias como mães e as suas mães/ filhas como mães, principalmente no que concerne às práticas educativas e disciplinares e no carinho oferecido à criança. Esses dados vão ao encontro dos resultados deste estudo com pais, os quais embora se considerassem diferentes em alguns aspectos, percebiam no pai um modelo a ser seguido, valorizando as mesmas dimensões no cuidados dos filhos.

\section{Considerações Finais}

Ao serem considerados os objetivos deste estudo, pretendeu-se entender como pais vivenciam a sua experiência de paternidade e como estes percebem as vivências de seus próprios pais. Durante as entrevistas e posterior análise observou-se que, enquanto o pai se descrevia como pai, aspectos relacionados com as experiências e representações vividas com seu próprio pai emergiam em suas falas, sem que fossem feitas perguntas específicas do roteiro para tanto. Este fato fez com que se tornasse difícil a análise dos dados em categorias distintas, tamanho era o entrelaçamento entre esses assuntos. Por outro lado, percebe-se que o cruzamento entre as diferentes representações e experiências de si como pai e com o próprio pai estão no cerne da construção da paternidade. Assim, a constituição e o exercício da paternidade desses pais parecem ser compostos pelas representações do que o homem acha que é e o que aprendeu com o próprio pai.

O pai procura compor um retrato de si mesmo, descrevendo as suas características como pai, o que costuma fazer com seu filho tanto no dia-a-dia como em termos do que pensa sobre a educação de um filho e da sua criação como um todo. É neste contexto que pode ser percebido o quanto a experiência como filho e a paternidade exercida pelo pai influencia na sua autodescrição. Esta descrição revela que o homem tenta alcançar uma posição ideal entre a sua experiência como pai e como filho, aceitando eventuais falhas - suas e do próprio pai-reconhecendo que as suas intenções com o filho são as melhores, sendo os erros advindos da tentativa de fazer o melhor.

Neste sentido, os homens, agora também pais, vislumbram a paternidade exercida pelo próprio pai de maneira diferente de quando eram apenas filhos. As dificuldades que sentem talvez expliquem algumas atitudes tomadas pelo próprio pai, principalmente na sua infância e adolescência. No contexto atual, o filho passa a enxergar o esforço e as boas intenções do pai, ao mesmo tempo em que consegue visualizar o que ele poderia ter feito enquanto pai e não fez. Este aspecto remete ao homem as suas mágoas em relação ao próprio pai, mas oferece, sobretudo, a possibilidade de fazer diferente com o próprio filho.

As diferenças e semelhanças em relação ao próprio pai no modo de exercer a paternidade mostram que posições ambíguas são expressas: ao mesmo tempo em que os participantes indicam desejar reproduzir os acertos dos pais, também buscam não repetir os erros. Na maioria das vezes, mesmo citando características negativas do próprio pai, o participante não deixava de lembrar a entrevistadora de que o seu pai ainda era um bom pai. Os entrevistados, quando remetiam alguma característica negativa 
ao seu pai ou expunham algo que gostariam de fazer diferente com seu filho, frequentemente tentavam suavizar a sua fala trazendo elementos que aliviavam a culpa por estar "falando mal" do próprio pai, como "naquela época as coisas não funcionam como hoje", "tinha muitos filhos, por isso não dava atenção", "admiro a forma difícil como nos criou". Talvez a culpa por estar avaliando negativamente o próprio pai advenha da questão de que, no futuro, os recém-pais se tornarão avôs e, em consequência, passarão pelo mesmo movimento: do filho aceitar o que serve e o que não serve, repudiar. Além disso, invalidar completamente as experiências com o próprio pai poderia ser muito doloroso a esses participantes, pois seria reconhecer a ausência de um modelo ou mesmo que esse modelo é negativo.

Através do seu próprio pai, o homem procura constituir a sua forma de ser pai. O homem cria para si um novo pai, o qual possui características do pai que teve e da sua própria maneira de ser. Mesmo apontando as diferenças que possui em relação ao seu pai e o que gostaria de fazer diferente, questiona-se se o jovem pai consegue, de fato, colocar essas novas ideias em prática. Neste sentido, emerge o questionamento quanto à autodescrição como "participante". Todos os pais entrevistados colocaram-se como pais que participam da vida dos filhos de uma forma qualificada, sendo esta presença afetiva, carinhosa, atenta. Pergunta-se o quanto esta participação realmente acontece e o quanto o pai se coloca neste lugar por entender que esta seria a resposta esperada de um bom pai ou para ser coerente com as críticas feitas ao pai. Dessa forma, mesmo os pais se colocando como "participantes", os próprios entrevistados explicam que, devido ao trabalho, não conseguem permanecer o tempo que gostariam com seus filhos. A participação se resume, então, ao tempo que estes estão disponíveis e não à integralidade de tempo em que a criança precisa de cuidados, sendo a mãe ou a escola as principais responsáveis pela criança durante o dia. Cabe ressaltar que, neste trabalho, o foco foi oferecido à opinião dos homens enquanto pais e não a efetividade de suas ações.

Essa falta de consistência entre o discurso e o fazer paterno faz parte do momento sócio-histórico em que o homem, enquanto sujeito social e psíquico, tem vivenciado um período de transição na constituição do seu papel. O "ser pai" tem abrigado uma coexistência entre modelos provenientes dos sistemas patriarcal, moderno e pós-moderno, mistura que torna ainda mais singular a experiência de cada homem. Mesmo convivendo com estes modelos históricos, percebe-se que há um esforço dos participantes em envolver-se afetivamente com os filhos, demonstrando o amor e carinho que sentem, sem rechaçar os seus sentimentos ou valores associados à sua "masculinidade". Com relação a este último âmbito, é importante salientar que mesmo sofrendo intensa influência do modelo de homem moderno e patriarcal, o pai provedor e viril não foi mencionado nesta pesquisa como condição do ser pai. Os participantes não se posicionaram, em nenhum momento, como essencialmente provedores, mas sim colocaram as suas preocupações com o financeiro, de maneira natural. Não se pode negar que a preocupação financeira é uma questão real para as famílias, uma vez que, atualmente, educar um filho envolve grandes investimentos. Assim, considera-se que a paternidade é um fenômeno complexo, no qual inúmeros enfoques podem ser adotados para a sua compreensão. Para esta pesquisa, tivemos acesso apenas a uma geração de pais que, mesmo com relatos riquíssimos, não contemplam a grande amplitude da construção da paternidade ao longo do tempo. Sugere-se, para tanto, que as próximas pesquisas contemplem outras gerações de participantes, assim como outros instrumentos de coleta de dados, a exemplo de grupos focais de discussão.

\section{Referências}

Balancho, L. S. F. (2004). Ser pai: transformações intergeracionais na paternidade. Análise Psicológica, 2, 377-386.

Bardin, L. (1977). Análise de Conteúdo. Lisboa: Edições70.

Bornholdt, E. A., \& Wagner, A. (2005). A gravidez à luz da perspectiva paterna: aspectos relativos à transgeracionalidade. In A. Wagner (Org), Como se perpetua a família? A transmissão dos modelos familiares (pp.81-93). Porto Alegre: Artes Médicas.

Bornholdt, E. A., Wagner, A., \& Staudt, A. C. P. (2007). A vivência da gravidez do primeiro filho à luz da perspectiva paterna. Psicologia Clínica, 19(1), 75-92.

Cabreira, N. J., Tames-LeMonda, C., Bradley, R. H., Hofferth, S., \& Lamb, M. E. (2000). Fatherhood in the Twenty-First Century. Child Development, $71(1), 127-136$

Dias, A. C. G., \& Lopes, R. C. S. (2003). Representações de maternidade de mães jovens e suas mães. Psicologia em estudo, 8 (n. especial), 63-73.

Fein, R. A. (1978). Reseach on fathering: Social Policy and an Emergent Perspective. Journal of Social Issues, 34(1), 122-135.

Freitas, W. M. F., Coelho, E. A. C., \& Silva, A. T. M. C. (2007). Sentir-se pai: a vivência masculina sob o olhar de gênero. Cadernos de Saúde Pública, 23(1), 137-145.

Freitas, W. M. F., Silva, A. T. M. C., Coelho, E. A. C., Guedes, R. N., \& Costa, A. M. T. (2009). Paternidade: responsabilidade social do homem no papel de provedor. Revista de. Saúde Pública, 43(1), 85-90.

Fuster, E. G., \& Ochoa, G. M. (2000). La (in)definición de la familia. In E. G. Fuster \& G. Misitu (Orgs.), Psicologia Social de la Familia (pp. 35-62). Barcelona: Paidós Ibérica

Gomes, A. J. S., \& Resende, V. R. (2004). O pai presente: o desvelar da paternidade em uma família contemporânea. Psicologia: Teoria e Pesquisa, 20(2), 119-125.

Henningen, I., \& Guareschi, N. M. F. (2008). Os lugares dos pais e de mães na mídia contemporânea. Revista Interamericana de Psicologia, 42(1), 81-90.

Krob, A. D., Piccinini, C. A., \& Silva, M. R. (2009). A transição para a paternidade: da gestação do segundo mês de vida do bebê. Psicologia, USP, 20(2), 269-291.

Levandowski, D. C., \& Piccinini, C. A. (2006). Expectativas e sentimentos em relação à paternidade entre adolescentes e adultos. Psicologia: Teoria $e$ Pesquisa, 22(1), 17-28.

Masciadrelli, B. P., Pleck, J. H., \& Stuave, J. L. (2006). Fathers' role model perceptions: themes and linkages with involvement. Men and Masculinities, $9(23), 23-34$

Muraro, R. M. (1992). A mulher do terceiro milênio: uma história da mulher através dos tempos. Rio de Janeiro: Rosa dos Tempos.

Piccinini, C. A., Silva, M. R., Gonçalves, T. R., Lopes, R. C. S., \& Tudge, J. (2004). O envolvimento paterno durante a gestação. Psicologia: Reflexão \& Crítica, 17(3), 303-311.

Ramires, V. R. R. (1997). O exercício da paternidade hoje. Rio de Janeiro: Rosa dos Tempos.

Romanelli, G. (2003). Paternidade em famílias de camadas médias. Estudos e Pesquisas em Psicologia (UERJ), 2, 79-95.

Silva, M. R., \& Piccinini, C. A. (2007). Sentimentos sobre a paternidade e o envolvimento paterno: um estudo qualitativo. Estudos de Psicologia (Campinas), 24 (4), 561-573. 
Silva, M. M. V. A. (2007). O processo histórico de construção das concepções de paternidade. In J. L. Pereira, C. Fanelli, R. C. Pereira, \& S. Rios (Orgs), Sexualidade na Adolescência no Novo Milênio (pp. 54-65). Rio de janeiro: UFRJ.

Staudt, A. C. P., \& Wagner, A. (2008). Paternidade em tempos de mudança. Psicologia: Teoria e Prática, 10(1), 174-185.

Sutter, C., \& Bucher-Maluschke, J. S. N. F. (2008). Pais que cuidam dos filhos: a vivência masculina da paternidade participativa. Psico, 39 (1), 74-82.

Wall, G., \& Arnold, S. (2007). How involved is involved fathering? An exploration of the contemporary culture of fatherhood. Gender \& Society, 21, 508-527.

Weber, L. N. D., Selig, G. A., Bernardi, M. G., \& Salvador A. P. V. (2006) Continuidade dos estilos parentais através das gerações: transmissão intergeracional de estilos parentais. Paidéia (Ribeirão Preto), 16(35), 407-414.

Marília Reginato Gabriel, graduada em Psicologia pela Universidade Federal de Santa Maria, e mestranda no Programa de Pós-graduação em Psicologia da Universidade Federal do Rio Grande do Sul. Endereço para correspondência: Rua Cristóvão Colombo, 508/701, Bairro Floresta, Porto AlegreRS. CEP: 90640-000. Telefones: (51)3308-5145/(51)9930-0883. E-mail: gabrielmarilia@yahoo.com.br Ana Cristina Garcia Dias, doutora em Psicologia pela Universidade de São Paulo e pós-doutoranda no Programa de Pós-graduação em Psicologia pela Universidade Federal do Rio Grande do Sul, é professora do Programa de Pós-graduação em Psicologia da Universidade Federal de Santa Maria. E-mail: anacristinagarciadias@gmail.com 